\title{
Clinical application of the customizable PEEK healing abutment. A case report
}

BEZERRA, Fabio Jose Barbosa ${ }^{1}$; ARAUJO, Felipe Moura ${ }^{2}$; OLIVEIRA, Guilherme Jose Pimentel Lopes de ${ }^{3}$; GHIRALDINI, Bruna ${ }^{4}$

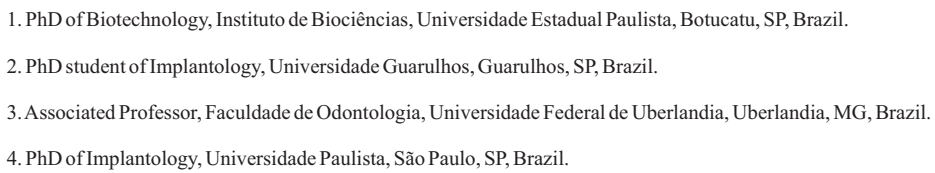

Author for Correspondence:

Fabio Jose Barbosa Bezerra

Gregorio Paes de Almeida St., 650

05450-000 - São Paulo - São Paulo - Brazil

E-mail: fabiobezerra@cenior.com.br

Submitted: January 21, 2020

Accepted: April 6, 2020

\section{ABSTRACT}

The aim of this case report was to present an indication of the PEEK as a material of customizable healing abutment. A 35-yearold male complained about the absence of the right upper first molar that had been previously extracted (2 years) due to unsuccessful endodontic treatment. After the anamnesis, the clinical and radiographic evaluation, a good bone availability that enables a dental implants placement was observed in the edentulous region. A dental implant with hybrid microgeometry and morse taper prosthetic connection was placed. A good primary stability was obtained (32 Ncm), however, the early loading technique was opted for this case instead of the immediate loading, since the implants placed in the posterior region requires to support a high masticatory loading force which could interfere with the healing process of the dental implant. Then, a customizable PEEK healing abutment was installed in order to define the prosthetic emergence profile. There were no signs of complications during the postoperative period, and after the twenty-eight-day healing period, a prosthetic interface for digital transfer was installed and intraoral scanning was performed. The prosthetic rehabilitation was performed by the CAD/CAM system, and a screwed prosthetic rehabilitation was installed at the same day. The patient was followed up for 12 months, and no signs or symptoms of peri-implant pathology or prosthetic complications were detected. The customizable PEEK healing abutment is a good option to induce a properly soft-tissue healing that enables an adequate prosthetic emergency profile.

Keywords: Dental implants. Dental abutments. Mouth rehabilitation. 


\section{INTRODUCTION}

The investigations of healing after the implant's placement have been traditionally focused on the interaction between the bone and implants surfaces, and the investigation of the integration of the soft tissues on the implant's components have been a secondary concern ${ }^{1-2}$. Tissue healing of peri-implant marginal tissue is considered a critical area for tissue integration due to the need for a good adaptation of bone tissue and peri-implant mucosa over the components of dental implants that should occur satisfactorily to promote the formation of an adequate emergency profile of the prostheses ${ }^{3-4}$.

Traditionally, the healing abutments are made of metal alloys (ie. titanium) based on the good outcomes that this material presented in these different types of tissue ${ }^{5-6}$. However, the soft tissue has a healing sequence mediated by different biological mediators and cells compared with the bone tissue1, and therefore, the same material does not have the same biological potential for healing different types of tissue $e^{4,7}$. In addition, the metal alloys changed the color of the marginal periimplant tissues creating aesthetic problems ${ }^{5,7}$. Indeed, the search for alternative materials that enhance the healing of soft tissue is absolutely necessary.

The polyetheretherketone (PEEK) has been used with success in the orthopedic surgeries with higher levels of success $^{8.9}$. In dentistry, the PEEK has been used as removable prothesis material10 as well as dental crowns ${ }^{11}$, and has presented good chemical stability, mechanical properties, aesthetic profile, and biocompatibility ${ }^{11}$. Recently, the PEEK has been indicated to be used as an implant abutment $t^{4,6}$. A pre-clinical study in dogs showed that despite the PEEK abutment presented more bone at the vestibular bone crest compared with the titanium abutments, the soft tissue healing pattern was not different between these abutments ${ }^{4}$. Another pre-clinical study in dogs showed that the titanium reinforced PPEK abutments presented high capacity to maintain the periimplant bone tissue during the healing period of 8 weeks compared with the titanium abutments ${ }^{6}$. The scientific documentation related to the clinical use of the PEEK healing abutment is quite low. So, the aim of this case report was to present an indication of the PEEK as a material of customizable healing abutment.

\section{CASE REPORT}

A 35-year-old male complained about the absence of the right upper first molar that had been previously extracted (2 years) due to unsuccessful endodontic treatment. After the anamnesis, the clinical and radiographic evaluation, a good bone availability that enabled a dental implant placement was observed in the edentulous region, and the use complementary surgical techniques was not required (ie. bone or soft-tissue grafts).

A local infiltrative anesthesia and antisepsis was performed previously of the surgical procedure. Then, a total open flap was performed and the bone perforation was made following the milling sequence recommended by the manufacturer of the dental implant under copiously irrigation with saline solution. Hereafter, a dental implant with hybrid microgeometry and morse taper connection was placed $(10 \times 5 \mathrm{~mm}$, Unitite Prime, S.I.N. Implant System, São Paulo, Brazil) (Figure 1 A-D). A good primary stability was obtained $(32 \mathrm{Ncm})$, however, the early loading technique was opted for this case instead of the immediate loading since the implant placed in the posterior region requires to support a high masticatory loading force which could interfere with the healing process of the dental implant. Then, a customizable PEEK healing abutment was installed (S.I.N. Implant System, São Paulo, Brazil) in order to define the prosthetic emergence profile (Figure $1 \mathrm{E}-\mathrm{G}$ ).

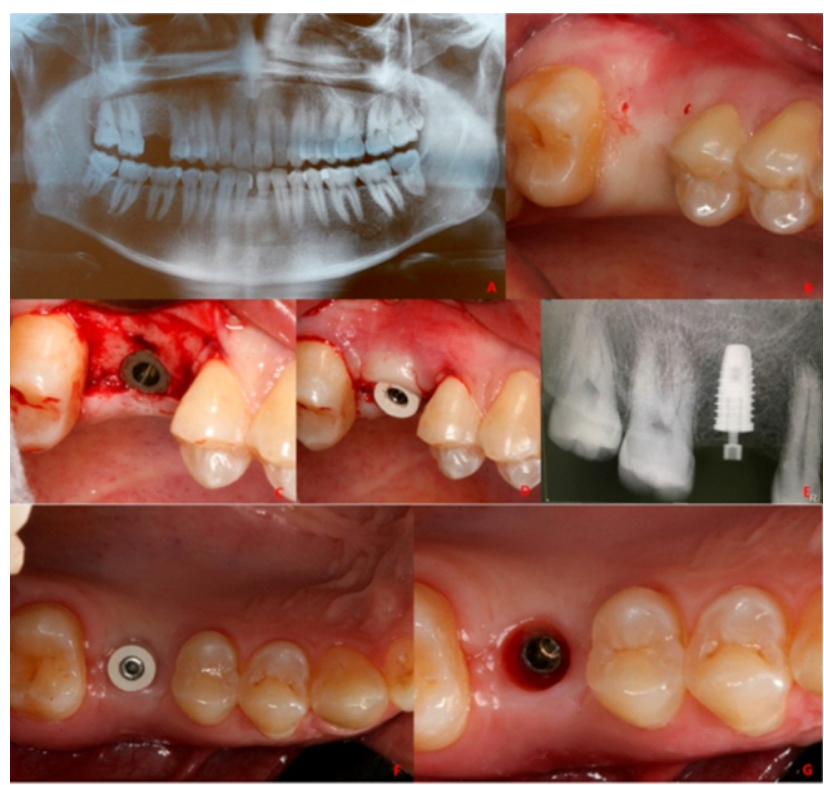

Figure 1 - A) Radiographic and B) clinical analysis showed a good bone availability that enables a dental implants placement; C) Dental implant placed; D) Customizable PEEK healing abutment installed; E) Periapical radiography showing the adequate position of the implant into de bone tissue; F) Clinical aspect 28-days after the surgical procedure; G) Aspect of the soft tissues profile.

There were no signs of complications during the postoperative period, and after the twenty-eight-day healing period, a prosthetic interface for digital transfer (Duotech, S.I.N. Implant System, São Paulo, Brazil) was installed and intraoral scanning was performed (Cerec Omnicam, 
Dentsply, Sirona, Germany) (Figure 2 A-C). Prosthetic rehabilitation was performed by the $\mathrm{CAD} / \mathrm{CAM}$ system, using a perforated lithium disilicate block (IPS E-Max, Ivoclar Vivadent, Liechtenstein), that were manufacture on a milling machine (MCXL, Denstisply, Sirona, Germany) (Figure $2 \mathrm{D}-\mathrm{H}$ ). Then, the screwed prosthetic rehabilitation was installed at the same day, with a mechanical torque of 20 $\mathrm{Ncm}$, that is the recommended by the manufacturer (Figure 2). The patient was followed up for 12 months, and no signs or symptoms of peri-implant pathology or prosthetic complications were detected. (Figure 2 I).

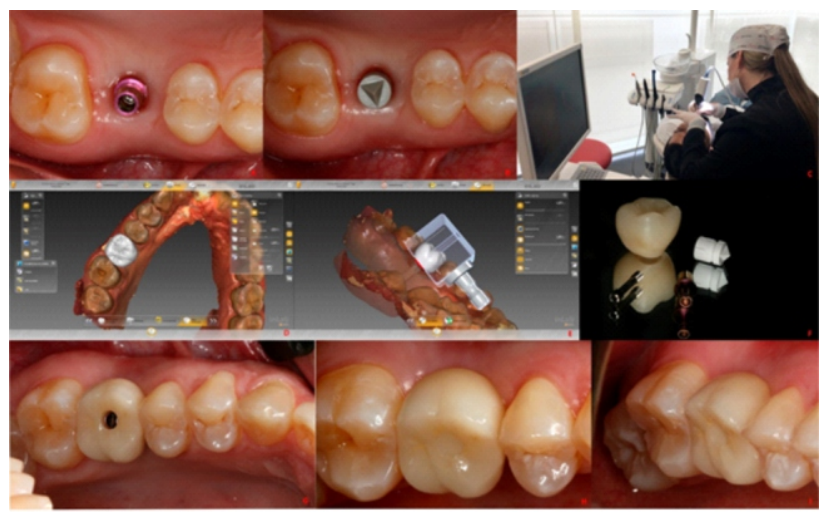

Figure 2 - A-B) A prosthetic interface for digital transfer; C) Intraoral scanning was performed; D-E) Planning of the crowns; F-G) Prosthetic rehabilitation performed by the CAD/CAM system, using a perforated lithium disilicate block; H) Clinical aspect after the crown installation; I) Clinical aspect after 12months of follow-up.

\section{DISCUSSION}

The successfully healing of peri-implant soft tissues is extremely important for maintaining the health of dental implants since it allows a biological seal that protects the bone tissue ${ }^{4,12}$. The use of abutment healing has the function to enable an adequate healing of peri-implant soft tissue, promoting a good profile of peri-implant mucosa that allows an adequate emergence profile of the prostheses supported by the implants ${ }^{13-14}$. In the present case report, this soft tissue healing pattern was successfully achieved associated with the use of the PEEK abutment healing.

The PEEK has been proposed as a good material to be used in implant dentistry due to the good biological properties associated with good biomechanical stability ${ }^{15}$. Biomechanical studies have been showed that the PEEK has an elasticity module similar to bone tissue, and high tensile strength which benefits the dissipation of occlusal forces ${ }^{16-17}$. In fact, theses evidences have been confirmed by clinical case reports that showed good outcomes related to the use of PEEK as a material for prothesis supported by implants ${ }^{18}$, and removable partial denture structures ${ }^{10}$.
In the present case report, it was observed that after 28 days the soft-tissue around the implant presented a good clinical condition and an adequate healing, which benefited the emergence profile of the prosthesis that was installed at that time. The good healing of the peri-implant soft tissue associated with the use of the customized PEEK abutment healing can be explained by the good biological properties that have been reported associated with the use of PEEK. An in vitro study demonstrated that PEEK induces fibroblast adhesion, proliferation and viability due to the overexpression of biological mediations that increases cell contractility and adhesion (Integrins), and an enhance of the synthesis of connective tissue matrix proteins (Collagen type I and Fibronectin) $)^{19}$. In addition, in vitro studies have also showed that PEEK impaired the adhesion of important biofilm-forming microorganisms (i.e. S. mutans) and periimplant pathogens (i.e. P.gingivalis, F.nucleatum) ${ }^{20}$.

It is worth noting that the integrity of the tissues around the implants and the good emergency profile of the prosthesis observed in this study is the combination of several factors that together generate good clinical outcomes. In addition to the use of customized PEEK abutment healing, the implant used in this case report presented a hybrid macrostructure that is cylindrical in the coronal region and gradually becoming tapered the apical region. This implants also presented compressive external threads and internal threads associated with a healing chamber that increases the stability of the clot, and these characteristics have been showed to enhance the osseointegration process ${ }^{21}$. In addition, these implants also presented a nanoactive surface coated with nHA that have been showed to stimulate the osteoblasts differentiation and activities $^{22-23}$. Futhermore, the implant presented a morse taper connection that has showed to be more efficient in the dissipation of the occlusal forces ${ }^{24}$, and in the prevention of the early bone $1 \mathrm{loss}^{25}$. Finally, the prothesis was manufactured with the aid of the CAD/CAM system that improves the adaptation of the crown over the abutments, promotes a good marginal sealing, low rate of prosthetic complications, and high level of patient's satisfaction ${ }^{26-27}$.

\section{CONCLUSION}

It can be concluded that the use of PEEK healing abutment enables an adequate prosthetic emergence profile due to the good outcomes on the healing pattern of the soft tissue. 


\section{REFERENCES}

1. Salvi GE, Bosshardt DD, Lang NP, Abrahamsson I, Berglundh T, Lindhe J, et al. Temporal sequence of hard and soft tissue healing around titanium dental implants. Periodontol 2000. 2015;68(1):135-52.

2. Atsuta I, Ayukawa Y, Kondo R, Oshiro W, Matsuura Y, Furuhashi A, et al. Soft tissue sealing around dental implants based on histological interpretation. J Prosthodont Res. 2016;60(1):3-11.

3. Sculean A, Gruber R, Bosshardt DD. Soft tissue wound healing around teeth and dental implants. J Clin Periodontol. 2014;41(Suppl 15):S6-22

4. Rea M, Ricci S, Ghensi P, Lang NP, Botticelli D, Soldini C. Marginal healing using Polyetheretherketone as healing abutments: an experimental study in dogs. Clin Oral Implants Res. 2017;28(7):e46-50.

5 Sicilia A, Quirynen M, Fontolliet A, Francisco H, Friedman A, Linkevicius T, et al. Long-term stability of peri-implant tissues after bone or soft tissue augmentation. Effect of zirconia or titanium abutments on peri-implant soft tissues. Summary and consensus statements. The 4th EAO Consensus Conference 2015. Clin Oral Implants Res. 2015;26(Suppl 11):148-52.

6. Maté Sánchez de Val JE, Gómez-Moreno G, Pérez-Albacete Martínez C, Ramírez-Fernández MP, Granero-Marín JM, Gehrke SA, et al. Peri-implant tissue behavior around non-titanium material: experimental study in dogs. Ann Anat. 2016;206:104-9.

7. Martínez-Rus F, Prieto M, Salido MP, Madrigal C, Özcan M, Pradíes G. A clinical study assessing the influence of anodized titanium and zirconium dioxide abutments and peri-implant soft tissue thickness on the optical outcome of implant-supported lithium disilicate single crowns. Int J Oral Maxillofac Implants. 2017;32(1):156-63.

8. Jiya TU, Smit T, van Royen BJ, Mullender M. Posterior lumbar interbody fusion using non resorbable poly-ether-ether-ketone versus resorbable poly-L-lactide-co-D,L-lactide fusion devices. Clinical outcome at a minimum of 2-year follow-up. Eur Spine J. 2011;20(4):618-22

9. Kojic N, Rangger C, Özgün C, Lojpur J, Mueller J, Folman Y, et al. Carbon-fibre-reinforced PEEK radiolucent intramedullary nail for humeral shaft fracture fixation: technical features and a pilot clinical study. Injury. 2017;48(Suppl 5):S8-11.

10. Zoidis P, Papathanasiou I, Polyzois G. The use of a modified polyether-ether-ketone (PEEK) as an alternative framework material for removable dental prostheses. A clinical report. J Prosthodont. 2016;25(7):580-4.

11. Najeeb S, Zafar MS, Khurshid Z, Siddiqui F. Applications of polyetheretherketone (PEEK) in oral implantology and prosthodontics. J Prosthodont Res. 2016;60(1):12-9.

12. López-López PJ, Mareque-Bueno J, Boquete-Castro A, AguilarSalvatierra Raya A, Martínez-González JM, Calvo-Guirado JL. The effects of healing abutments of different size and anatomic shape placed immediately in extraction sockets on peri-implant hard and soft tissues. A pilot study in foxhound dogs. Clin Oral Implants Res. 2016;27(1):90-6.

13. Molina A, Sanz-Sánchez I, Martín C, Blanco J, Sanz M. The effect of one-time abutment placement on interproximal bone levels and periimplant soft tissues: a prospective randomized clinical trial. Clin Oral Implants Res. 2017;28(4):443-52.
14. Susin C, Finger Stadler A, Fiorini T, de Sousa Rabelo M, Ramos UD, Schüpbach P. Safety and efficacy of a novel anodized abutment on soft tissue healing in Yucatan mini-pigs. Clin Implant Dent Relat Res. 2019;21(Suppl 1):34-43.

15. Schubert O, Reitmaier J, Schweiger J, Erdelt K, Güth JF. Retentive force of PEEK secondary crowns on zirconia primary crowns over time. Clin Oral Investig. 2019;23(5):2331-8.

16. Kurtz SM, Devine JN. PEEK biomaterials in trauma, orthopedic, and spinal implants. Biomaterials. 2007;28(32):4845-69.

17. Benli M, Eker Gümü? B, Kahraman Y, Gökçen-Rohlig B, Evlio?lu G, Huck O, et al. Surface roughness and wear behavior of occlusal splint materials made of contemporary and high-performance polymers. Odontology. 2020;108(2):240-50.

18. Parmigiani-Izquierdo JM, Cabaña-Muñoz ME, Merino JJ, SánchezPérez A. Zirconia implants and peek restorations for the replacement of upper molars. Int J Implant Dent. 2017;3(1):5.

19. Wang X, Lu T, Wen J, Xu L, Zeng D, Wu Q, et al. Selective responses of human gingival fibroblasts and bacteria on carbon fiber reinforced polyetheretherketone with multilevel nanostructured $\mathrm{TiO} 2$. Biomaterials. 2016;83:207-18.

20. Montero JF, Barbosa LC, Pereira UA, Barra GM, Fredel MC, Benfatti $\mathrm{CA}$, et al. Chemical, microscopic, and microbiological analysis of a functionalized poly-ether-ether-ketone-embedding antibiofilm compounds. J Biomed Mater Res A. 2016;104(12):3015-20.

21. Coelho PG, Marin C, Granato R, Bonfante EA, Lima CP, Oliveira S, et al. Alveolar buccal bone maintenance after immediate implantation with a surgical flap approach: a study in dogs. Int J Periodontics Restorative Dent. 2011;31(6):e80-6.

22. Bezerra F, Ferreira MR, Fontes GN, da Costa Fernandes CJ, Andia DC, Cruz NC, et al. Nano hydroxyapatite-blasted titanium surface affects pre-osteoblast morphology by modulating critical intracellular pathways. Biotechnol Bioeng. 2017;114(8):1888-98.

23. Martinez EF, Ishikawa GJ, de Lemos AB, Barbosa Bezerra FJ, Sperandio M, Napimoga MH. Evaluation of a titanium surface treated with hydroxyapatite nanocrystals on osteoblastic cell behavior: an in vitro study. Int J Oral Maxillofac Implants. 2018;33(3):597-602.

24. Sousa RM, Simamoto-Junior PC, Fernandes-Neto AJ, Sloten JV, Jaecques SV, Pessoa RS. Influence of connection types and implant number on the biomechanical behavior of mandibular full-arch rehabilitation. Int J Oral Maxillofac Implants. 2016;31(4):750-60.

25. Pessoa RS, Sousa RM, Pereira LM, Neves FD, Bezerra FJ, Jaecques $\mathrm{SV}$, et al. Bone remodeling around implants with external hexagon and morse-taper connections: a randomized, controlled, split-mouth, clinical trial. Clin Implant Dent Relat Res. 2017;19(1):97-110.

26. Wittneben JG, Gavric J, Belser UC, Bornstein MM, Joda T, Chappuis $\mathrm{V}$, et al. Esthetic and clinical performance of implant-supported allceramic crowns made with prefabricated or CAD/CAM zirconia abutments: a randomized, multicenter clinical trial. J Dent Res. 2017;96(2):163-70.

27. Mangano F, Veronesi G. Digital versus analog procedures for the prosthetic restoration of single implants: a randomized controlled trial with 1 year of follow-up. Biomed Res Int. 2018;18:5325032. 